\title{
Delayed recovery of a patient with obstructive azoospermia and a history of acute epididymitis
}

\author{
Seung-Hun Song ${ }^{1}$, Jeong Yun Shim², Suye Sung ${ }^{3}$, Young Sun $\mathrm{Her}^{3}$, Mihee $\mathrm{Oh}^{3}$, Dong Hyuk Shin ${ }^{3}$, Jinil Lee ${ }^{3}$, Jeoungwon Baek ${ }^{3}$, \\ Woo Sik Lee ${ }^{4}$, Dong Suk Kim ${ }^{1}$
}

Departments of ${ }^{1}$ Urology and ${ }^{2}$ Pathology, ${ }^{3}$ Andrology Lab, and ${ }^{4}$ Department of Obstetrics and Gynecology, Fertility Center, CHA Gangnam Medical Center, CHA University, Seoul, Korea

Obstructive azoospermia caused by acute epididymitis is usually permanent, and microsurgical vasoepididymostomy is the only reconstructive treatment option. There have been no reports of delayed recovery of sperm count after over 1 year in a patient with obstructive azoospermia related to history of acute epididymitis. We present a young male patient who had azoospermia and a history of acute epididymitis who experienced delayed recovery, with complete restoration of sperm production and the ability to conceive naturally.

Keywords: Azoospermia; Epididymitis; Infertility; Male

\section{Introduction}

Obstructive azoospermia is a urologic condition that occurs in fewer than $1 \%$ of all men, but in approximately $10 \%-15 \%$ of infertile men [1]. Obstructive azoospermia is caused by an anatomical block in the epididymis, vas deferens, or ejaculatory duct in the prostate gland. The underlying etiology may be infection, iatrogenic injury, or a genetic or congenital condition. Acute epididymitis is a common genitourinary condition that may lead to a transient deterioration of sperm quality or permanent epididymal and vasal obstruction [2]. Pathogens can induce intense inflammatory reactions, resulting in secondary scarring and obstruction of the epididymis and vas deferens [3]. Obstructive azoospermia from acute epididymitis usually does not resolve without surgical treatment. Microsurgical vasoepi-

Received: Mar 21, 2019 · Revised: Apr 15, 2019 · Accepted: May 2, 2019 Corresponding author: Dong Suk Kim

Department of Urology, CHA Gangnam Medical Center, CHA University, 566

Nonhyeon-ro, Gangnam-gu, Seoul 06135, Korea

Tel: +82-2-3468-2677 Fax:+82-2-3468-3415 E-mail:dskim100@chamc.co.kr

*This work was supported by the National Research Foundation of Korea (NRF) grant funded by the Korea government (MSIT) (No. 2019R1G1A1002237).

This is an Open Access article distributed under the terms of the Creative Commons Attribution Non-Commercial License (http://creativecommons.org/licenses/by-nc/4.0/) which permits unrestricted non-commercial use, distribution, and reproduction in any medium, provided the original work is properly cited. didymostomy is the only available reconstructive surgical treatment for obstructive azoospermia secondary to acute epididymitis. No previous study has reported the delayed recovery of sperm count more than 1 year after treatment in a patient with obstructive azoospermia secondary to acute epididymitis. Here, we present a case of a young man with obstructive azoospermia associated with a history of acute epididymitis who experienced delayed recovery, and then produced sufficient sperm for natural conception.

\section{Case}

A 20-year-old male patient visited our andrology clinic for a fertility evaluation. He had engaged in regular sexual intercourse with his 20-year-old female partner without contraception for 6 months, but she did not get pregnant. Twelve months previously, he had received 3 weeks of treatment with oral antibiotics for right acute epididymitis. He had no chronic medical diseases, took no daily medications, had no history of trauma to the scrotum or genitalia, and had no symptoms related to testosterone deficiency. His libido, erectile function, and ejaculation volume were normal. The physical examination indicated he had a healthy and normal male appearance, a body height of $174 \mathrm{~cm}$, and a body mass index of $23.1 \mathrm{~kg} / \mathrm{m}^{2}$. He had a normal male pattern of hair on the face, body, axillary regions, and 

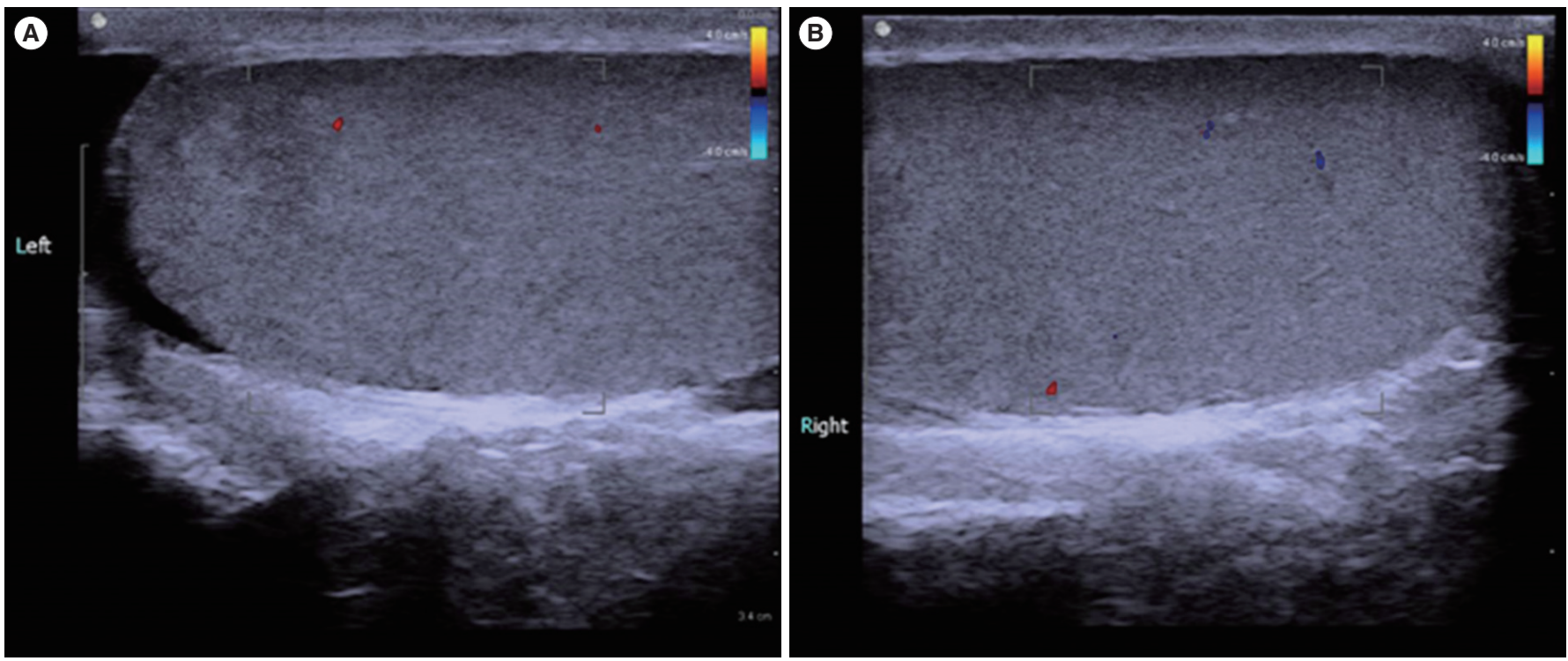

Figure 1. Doppler scrotal ultrasonography showed normal size, echogenicity and blood flow of both testis (A, left testis; B, right testis).

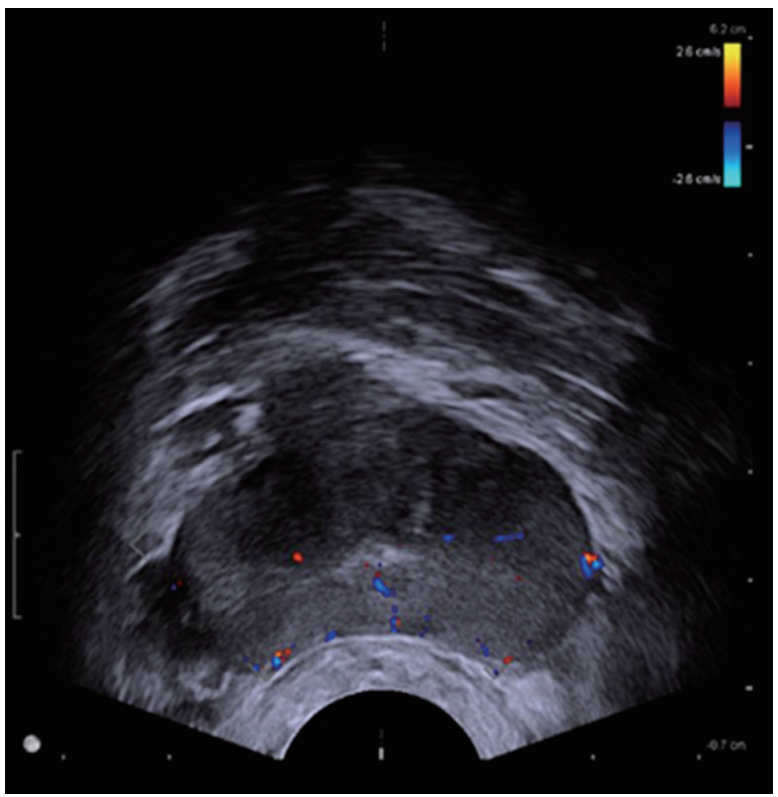

Figure 2. Transrectal prostate ultrasonography showed normal echogenicity and blood flow of prostate without any obstructive lesion.

pubic regions, and did not have gynecomastia. Examination of the external genitalia indicated they were normal, and the stretched penis length was $13 \mathrm{~cm}$. Both testes were normally positioned in the scrotum, had normal consistency on palpation, and were normal in size (20 mL each).

No abnormalities of the epididymis and vas deferens were noted. Semen analysis showed azoospermia, with a volume of $1.4 \mathrm{~mL}$ and small amounts of inflammatory cells $\left(0.7 \times 10^{6} / \mathrm{mL}\right.$; normal range, $<1 \times 10^{6} / \mathrm{mL}$ ). There were normal levels of serum follicle-stimulating

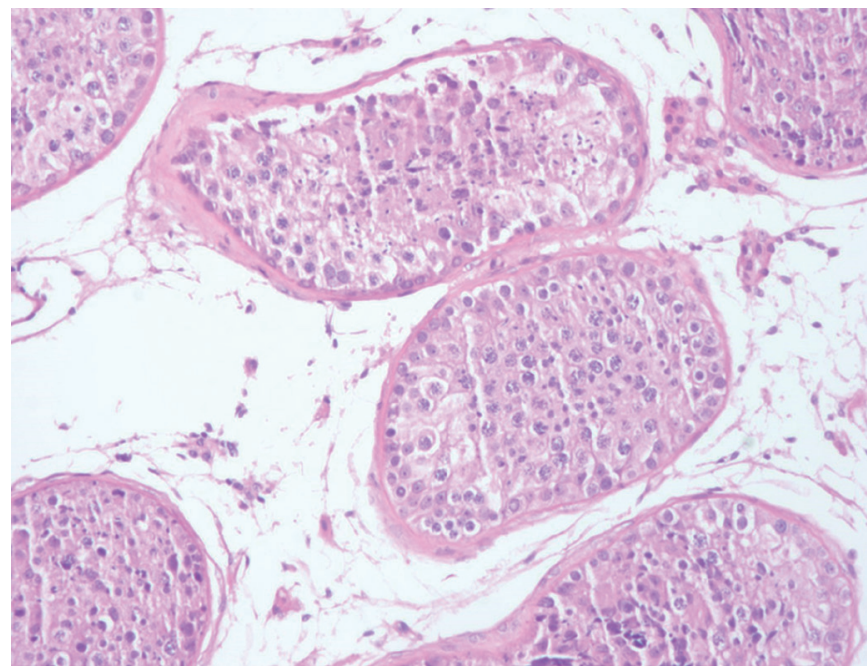

Figure 3. The histology of a testis biopsy revealed normal spermatogenesis $(H \& E, \times 200)$.

hormone (4.48 mlU/mL; normal range, 1.5-12.4 mlU/mL), luteinizing hormone ( $4.29 \mathrm{mlU} / \mathrm{mL}$; normal range, $1.24-8.62 \mathrm{mlU} / \mathrm{mL})$, prolactin ( $14.3 \mathrm{ng} / \mathrm{mL}$; normal range, 4.04-15.2 $\mathrm{ng} / \mathrm{mL})$, and testosterone (3.40 $\mathrm{ng} / \mathrm{mL}$; normal range, $2.49-8.36 \mathrm{ng} / \mathrm{mL}$ ). A second semen analysis 2 weeks later also showed azoospermia with volume of $1.7 \mathrm{~mL}$. There was no sperm in the post-ejaculatory urine.

We performed ultrasonography of the scrotum and prostate. Doppler ultrasound of the scrotum indicated normal size, echogenicity, and blood flow of the testis and epididymis, and no definite tubular ectasia of the rete testis or the epididymis (Figure 1). Transrectal prostate ultrasonography showed no obstructive lesion in the prostate and no seminal vesicle dilatation or ejaculatory obstruction, but a 
slightly enlarged prostate volume of $24 \mathrm{~mL}$ (Figure 2). To confirm testicular spermatogenesis, we performed a biopsy of the left testis under local anesthesia, and the result indicated normal spermatogenesis in the seminiferous tubules (Figure 3). Our final diagnosis was obstructive azoospermia related to a history of acute epididymitis.

The patient was lost to follow-up until he visited again 18 months later because his female partner had become pregnant. A follow-up semen analysis indicated normal semen volume $(3.8 \mathrm{~mL}$; normal range, $\geq 1.5 \mathrm{~mL})$, sperm concentration $\left(35 \times 10^{6} / \mathrm{mL}\right.$; normal range, $\geq 15 \times 10^{6} / \mathrm{mL}$ ), motility (47\%; normal range, $\geq 40 \%$ ), and strict normal morphology (4\%; normal range, $\geq 4 \%$ ). We recommended an additional semen analysis 1 month later, but the patient was lost to further follow-up.

\section{Discussion}

We describe a young male patient with azoospermia and a history of acute epididymitis who experienced delayed recovery, as indicated by adequate sperm production and the ability to conceive naturally. Acute epididymitis can have several etiologies, including bacterial ascent, viral and fungal infection, drug-induced epididymitis, rheumatic disease, trauma, and sterile urine reflux [2]. Bacterial ascent through the urogenital tract plays a important role in the etiology of acute epididymitis, with common microorganisms including typical uropathogens such as Escherichia coli and sexually transmitted pathogens [4]. Nicholson et al. [5] reported that the annual incidence of acute epididymitis was approximately 400 per 100,000 men. The symptoms of acute epididymitis are typically unilateral scrotal pain and epididymal swelling. Epididymitis can also be asymptomatic [6]. Bilateral involvement is reported to occur in $4 \%$ of patients. Because $60 \%$ of patients with acute epididymitis show testicular involvement, many researchers use the term epididymo-orchitis rather than epididymitis [7]. Urogenital infections, including acute epididymitis, can have various effects on male fertility. These include direct or indirect damage to sperm quality and function by the pathogens themselves or reactive oxygen species, inflammationrelated obstruction of the reproductive tract, inhibition of spermatogenesis through direct effects of the pathogens or their components, and induction of a humoral immune response to sperm [8]. The deterioration of sperm concentration in the ejaculate during acute epididymitis is usually reversible within 3 to 6 months [8]. However, acute epididymitis can cause an intense inflammatory reaction, leading to secondary scarring and obstruction of the epididymis; therefore, reduced sperm quality or azoospermia can remain permanent even after treatment. Rusz et al. [9] reported in a systematic review that after treatment of urogenital infections, persistent azoospermia occurred in approximately $10 \%$ of patients and oligozoospermia in another $30 \%$ of patients.

The mechanism of obstructive azoospermia in unilateral epididymitis is not clear. In acute epididymitis, complete obstruction of the epididymis as well as of the vas deferens or the ejaculatory duct may develop as a result of bacterial ascent through the urogenital tract. However, acute epididymitis can be asymptomatic [6], and subclinical contralateral epididymitis might be present in patients diagnosed with unilateral epididymitis. In a small study of biopsy findings, Osegbe reported that patients presenting with unilateral acute epididymitis who underwent contralateral testicular biopsy showed evidence of gonadal damage and azoospermia in the contralateral testis, suggesting the presence of subclinical bilateral involvement [10].

A transient state of azoospermia may be caused not only by urogenital infection, but also by toxic, environmental, or iatrogenic factors such as testosterone replacement therapy [11]. Nutritional deficiencies, heat exposure, and various endocrinopathies can lead to transient azoospermia [12]. Temporary azoospermia can also occur following systemic infections, and can last for 2 to 3 months [11]. Odom and Kutteh [13] reported a case of azoospermia secondary to an acute febrile episode from meningitis, in which the sperm count recovered 5 months later with a successful natural pregnancy.

If azoospermia continues for more than 6 months after treatment for acute epididymitis, then obstructive azoospermia due to secondary scarring and obstruction of the epididymis is likely, and microsurgical vasoepididymostomy could be considered as a treatment option. There have been no previous reports of delayed recovery from obstructive azoospermia secondary to acute epididymitis more than 12 months after medical treatment. The mechanism of late recovery of azoospermia in our patient is uncertain. Because pathogenic bacterial ascent through the urogenital tract is the most important cause of acute epididymitis, it is possible that acute epididymitis occurred together with acute prostatitis, potentially resulting in swelling of the epididymal tubules and ejaculatory duct. The transient obstruction that may have resulted from edema of the small tubules of the epididymis and the ejaculatory duct following an epididymal and/or prostatic infection could take a relatively long time to resolve, even over 1 year. If this hypothesis is correct, it could explain this patient's very delayed recovery from azoospermia more than 1 year after acute epididymitis. The limitations of this case report include the lack of semen analysis at the time of acute epididymitis treatment and the absence of medical information regarding the patient's contralateral epididymal status or the possibility of a concomitant prostate infection in the acute phase of epididymitis. This is a rare case report of delayed recovery from obstructive azoospermia that occurred more than 1 year after acute epididymitis treatment. 


\section{Conflict of interest}

No potential conflict of interest relevant to this article was reported.

\section{ORCID}

Seung-Hun Song https://orcid.org/0000-0003-4649-9129

Jeong Yun Shim https://orcid.org/0000-0002-4628-6660

Suye Sung https://orcid.org/0000-0002-4581-3182

Young Sun Her https://orcid.org/0000-0003-3678-2801

Mihee Oh https://orcid.org/0000-0002-2880-5738

Dong Hyuk Shin https://orcid.org/0000-0002-9789-237X

Jinil Lee $\quad$ https://orcid.org/0000-0001-5102-3278

Jeoungwon Baek https://orcid.org/0000-0003-2686-6358

Woo Sik Lee https://orcid.org/0000-0002-2329-1774

Dong Suk Kim https://orcid.org/0000-0001-7350-0303

\section{Author contributions}

Conceptualization: SHS, SS, DSK. Data curation: JYS, YSH, MO, DHS, WSL, JB. Formal analysis: SHS, DSK. Funding acquisition: DSK. Methodology: SHS, JL. Project administration: SHS. Visualization: DSK. Writing - original draft: SHS, DSK. Writing - review \& editing: DSK.

\section{References}

1. Chen XF, Chen B, Liu W, Huang YP, Wang HX, Huang YR, et al. Microsurgical vasoepididymostomy for patients with infectious obstructive azoospermia: cause, outcome, and associated factors. Asian J Androl 2016;18:759-62.

2. Berardinucci D, Zini A, Jarvi K. Outcome of microsurgical reconstruction in men with suspecte epididymal obstruction. J Urol 1998;159:831-4.

3. Pelliccione F, Cordeschi G, Giuliani V, D'Abrizio P, Necozione S, Ne- gri L, et al. The contractile wall of the caput epididymidis in men affected by congenital or postinflammatory obstructive azoospermia. J Androl 2004;25:417-25.

4. Pilatz A, Hossain H, Kaiser R, Mankertz A, Schuttler CG, Domann E, et al. Acute epididymitis revisited: impact of molecular diagnostics on etiology and contemporary guideline recommendations. Eur Urol 2015;68:428-35.

5. Nicholson A, Rait G, Murray-Thomas T, Hughes G, Mercer CH, Cassell J. Management of epididymo-orchitis in primary care: results from a large UK primary care database. Br J Gen Pract 2010;60: e407-22.

6. Bayasgalan G, Naranbat D, Radnaabazar J, Lhagvasuren T, Rowe PJ. Male infertility: risk factors in Mongolian men. Asian J Androl 2004;6:305-11.

7. Schuppe HC, Meinhardt A, Allam JP, Bergmann M, Weidner W, Haidl G. Chronic orchitis: a neglected cause of male infertility? Andrologia 2008;40:84-91.

8. Schuppe HC, Pilatz A, Hossain H, Diemer T, Wagenlehner F, Weidner W. Urogenital infection as a risk factor for male infertility. Dtsch Arztebl Int 2017;114:339-46.

9. Rusz A, Pilatz A, Wagenlehner F, Linn T, Diemer T, Schuppe HC, et al. Influence of urogenital infections and inflammation on semen quality and male fertility. World J Urol 2012;30:23-30.

10. Osegbe DN. Testicular function after unilateral bacterial epididymo-orchitis. Eur Urol 1991;19:204-8.

11. Lahav-Baratz S, Rothschild E, Grach B, Koifman M, Shiloh H, Ishai $D$, et al. The value of sperm pooling and cryopreservation in patients with transient azoospermia or severe oligoasthenoteratozoospermia. Hum Reprod 2002;17:157-60.

12. Martin-du Pan RC, Campana A. Physiopathology of spermatogenic arrest. Fertil Steril 1993;60:937-46.

13. Odom N, Kutteh W. Transient azoospermia caused by a febrile episode secondary to meningitis. J Gynecol Womens Health 2017;7:555707. 